\title{
The Making of a Good Woman: Why Do Pre-School Girls in the KSA Have to Navigate Two Different Worlds to Survive Socially?
}

\author{
Mona Al zahrani ${ }^{1}$ \\ ${ }^{1}$ School of Education, Oxford Brookes University, UK \\ Correspondence: Mona Al zahrani, School of Education, Oxford Brookes University, UK. E-mail: \\ dralzahrani13@gmail.com
}

Received: December 10, 2020 Accepted: January 22, 2021 Online Published: January 26, 2021

doi:10.5539/jel.v10n1p94 URL: https://doi.org/10.5539/jel.v10n1p94

\begin{abstract}
The article discusses how young females navigate and develop a solid sense of two worlds in order to be perceived a 'good girl' that can be positioned within the society and maintain the female gender identity that is expected of them in the future. One world is where they are expected to show all the attributes of femininity and beauty and the other world is where they are required to develop a strong sense of 'self-control', to be 'a good girl' who complies with societal confinements and restrictions on their female body and mobility. This article has emerged from a doctorate research entitled: The Making of a Good Woman: Analysing children's narratives on female gender identity and role in pre-school Saudi Arabia. It was a study into how female gender identity is constructed in the Kingdom of Saudi Arabia (KSA) by analysing children's (young girls 4-6 years) perspectives within pre-school, exploring their perceptions of female identity and role in the KSA. Exploring the ways in which gender identities were interpreted and manifested; studying the influences, apparent ideologies and discourses that affect female gender construction. Through the analysis of the data, interesting results emerged that exposed the consideration of gender roles, permissible and non-permissible behaviour and attitudes, and the realisation that female gender is often constructed, in the KSA, through fear and restrictions.
\end{abstract}

Keywords: Saudi Arabia, pre-school, female, gender, identity, role, two worlds, navigate

\section{Introduction}

Today many consider Saudi Arabia a "closed and conserved" society due to its tribal, cultural and religious features (Maisel \& Shoup, 2009). This research pertained to how young girls in Saudi Arabia acquire their attitudes on what is expected of them as females. The participant children were from different economical and social backgrounds and different regional tribes (an important consideration in the KSA). The tribal traditions in Saudi Arabia represent an important source for societal and national values that have affected and influenced the formation of the country in different stages (Kostiner, 1990). The tribal traditions and hierarchy in the region are recognised as presenting centralised figures of authority; however, today they are only deemed to be acceptable if they are consistent with the main teachings of Islam. Any given society influences a child's developing knowledge through interactions with more experienced peers, teachers, parents, and others (Vygotsky, 1978). There are strong influences on young girls from the Saudi State and from the adults with whom they are in contact concerning how females should act, and this has to be compared with what these children may be seeing on the Internet and/or other international media sources. There is thus the possibility of confusion for these children in attempting to create their own world and develop a sense of belonging. Bronfenbrenner's ecological theory (1979) involving children's micro and macro worlds can help to identify and describe the many influences on young children. His theory was adapted and remodeled (see Figure 3) for this research, in order to look at the influences on female identity construction in the context of the KSA, to frame the children's worlds. The microworld includes the many influences on female development, such as cultural beliefs and experiences that can contribute to children's notions of identity. The significant others include experienced peers, teachers, parents, and other members of a society, all of whom can influence a child's development. In the macroworld, the Saudi Arabian government has dominant influences in the form of robust policies and notions of what or how a female should act. Identification of these worlds together with the children's narratives, were used to explore the reality of female gender perceptions in Saudi Arabia. These days, children in Saudi Arabia are often subjected to other influences such as the Internet and other media sources that can influence perceptions of 
identity. Consequently, complications can arise for young Saudi girls when they wish to establish an authentic sense of belonging to their culture and society.

\section{Early Childhood Education in Saudi Arabia and Its Influence}

Children in Saudi Arabia all attend single sex schools, except for preschool where both sexes are taught together. Traditionally, KSA Ministries have had separate departments for the education of males and females. This separation was justified as being required to ensure that girls do not deviate from the educational aims for females, safeguarding their role of being good mothers and wives (Al-ghamdi \& Abdul-aljawad, 2010). Even in the recent past, it was considered that KSA females should study only an Islamic based curriculum, and it is only recently that women have been able to study subjects other than religion and education in universities (Sedgwick, 2001). Education was intended to make women ready for careers in teaching and nursing, which are regarded as appropriate fields for women. The previous General Ministry for girls' education worked under the supervision of religiously conservative scholars and thus the curriculum was very different from that detailed by the Ministry of Education for boys.

Presently, major changes have occurred in Saudi Arabian educational policy in the light of the SaudiVision 2030, wherein it states, "we will prepare a modern curriculum focused on rigorous standards". It also goes on to say, "Saudi women are yet another great asset. With over 50 percent of our university graduates being female." Two recent publications concerning preschool education (Rajab \& Wright, 2018a; Rajab \& Wright, 2018b) deal with (a) the new curriculum involving child-centred learning and how this may be difficult to implement in Saudi preschools; and (b) whether children are carrying out their gender roles correctly within the scope of the new curriculum. The second paper used interviews with the preschool teachers and included a comment from one teacher that young boys find it difficult to adjust, even just to attend school together with girls. Thus, the question of gender in Saudi preschools can be seen to be quite different from the remainder of Saudi education and also from that in Western countries where boys and girls are largely treated in a similar fashion. It is interesting to note that the aforementioned research involves adults and their perceptions, and not children. Thus, this study with children is of great importance, as it explores the beginnings of gender construction for young KSA girls, exploring the everyday nuances and routines of these childrens' lives whilst analysing their perspectives on gender and what they feel female gender identity and role are.

\section{Methodology}

The research questions formed the basis of the study and methods were developed to answer these questions.:

- How can one identify and analyse how pre-school girls (4-6 years) in a pre-school setting in Saudi Arabia (KSA) interpret themselves as gendered beings?

- In which ways are gender identities manifested in narratives and stories and through ideologies and discourses?

- What are the influences on female gender construction in pre-school children and how do they shape and construct female gender identity and role?

This study gathered data, entirely from the pre-school children, over a period of three months using observations, story-telling, picture prompt cards, group interviews, drawings and annotations, i.e., 'multiple modes of expression' that provoked the girls' perceptions. In addition, a story book was devised specifically for use in the Saudi context to prompt responses.

Although the research was not approached through a 'narrative paradigm', it employed a narrative approach for data collection. This has been found to be useful by others working in educational research (e.g., Barone, 2001; Estola \& Elbaz-Luwisch, 2000). A narrative paradigm is based on communication theory first conceptualized by Walter Fisher (1984). This claims that most meaningful communication occurs via storytelling or reporting of events; and my study used both elements to encourage the children to share their perceptions. Story-telling (either by children or by others) is known as a practice that allows people the opportunity to make sense of their lives (Clough, 2002; MacIntyre, 1985) and it provides an inside view of a culture and how individuals can become socialised into a cultural setting (Christou, 2006). The approach also employed Bronfenbrenner's theories $(1962,1979,1986)$ and his socio-ecological system presents the vision of a female child in her social world and places her in the center. Another theory that was crucial was the post-structuralist theory of Davies (1989) and Walkerdine (1997) as these focused on identifying, exploring and analysing the linguistic and social functions of discourses; investigating how linguistics is 'produced and regulated', and its 'social effects' (Bové, 1990, p. 54).

Bronfenbrenner's ecological system theory gave me the bones of how a young girl's life and personality is 
shaped and formed through influences and allowed the conceptualization of the young girls' world within the context of the KSA. Post-structuralism gave me the flesh, the insight to see the origins of those influences, that is, where do they come from, what were their objectives, and what were the expected outcomes? The research was thus framed within a post-structuralist epistemological paradigm and this was used to question normative views and expectations of female gender identity and role in a Saudi context. This framework gave me the tools to consider the validity and scope of the normative views seemingly apparent in Saudi Arabia culture and to make distinctions between informed and prejudiced opinions. Importantly, the research also took into consideration both internal and external influences.

The school where the data were collected was a state school funded by the Ministry of Education in the KSA and located in Riyadh, the capital city. The pre-school setting is a kindergarten which educates male and female children together between the ages of 4-6 years.

\section{Results, Analysis and Discussion}

The following explores and discusses the results of the research and circumnavigates the two dominions necessary to be conceived 'a good girl' to be accepted by society and determines the customs and norms that frame and sustain the construction of the female gender identity and role in the KSA. The home, school and society create a triangle of construction; with each reinforcing the philosophy and stratagem of the other without contradictions between those three factors.

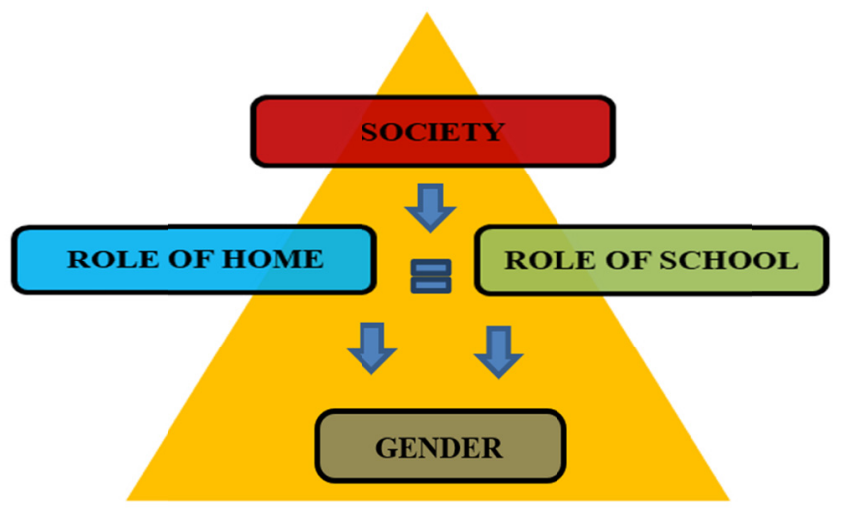

Figure 1. The main authorities that influence girls' gender identity

Source: Al Zahrani, 2016.

Females must negotiate their existence within the ideals and traditions embedded in the moral discourses they encounter that determine what makes a good woman. The diagram below demonstrates pictorially the processes of the construction of female gender identity and role in the KSA: 


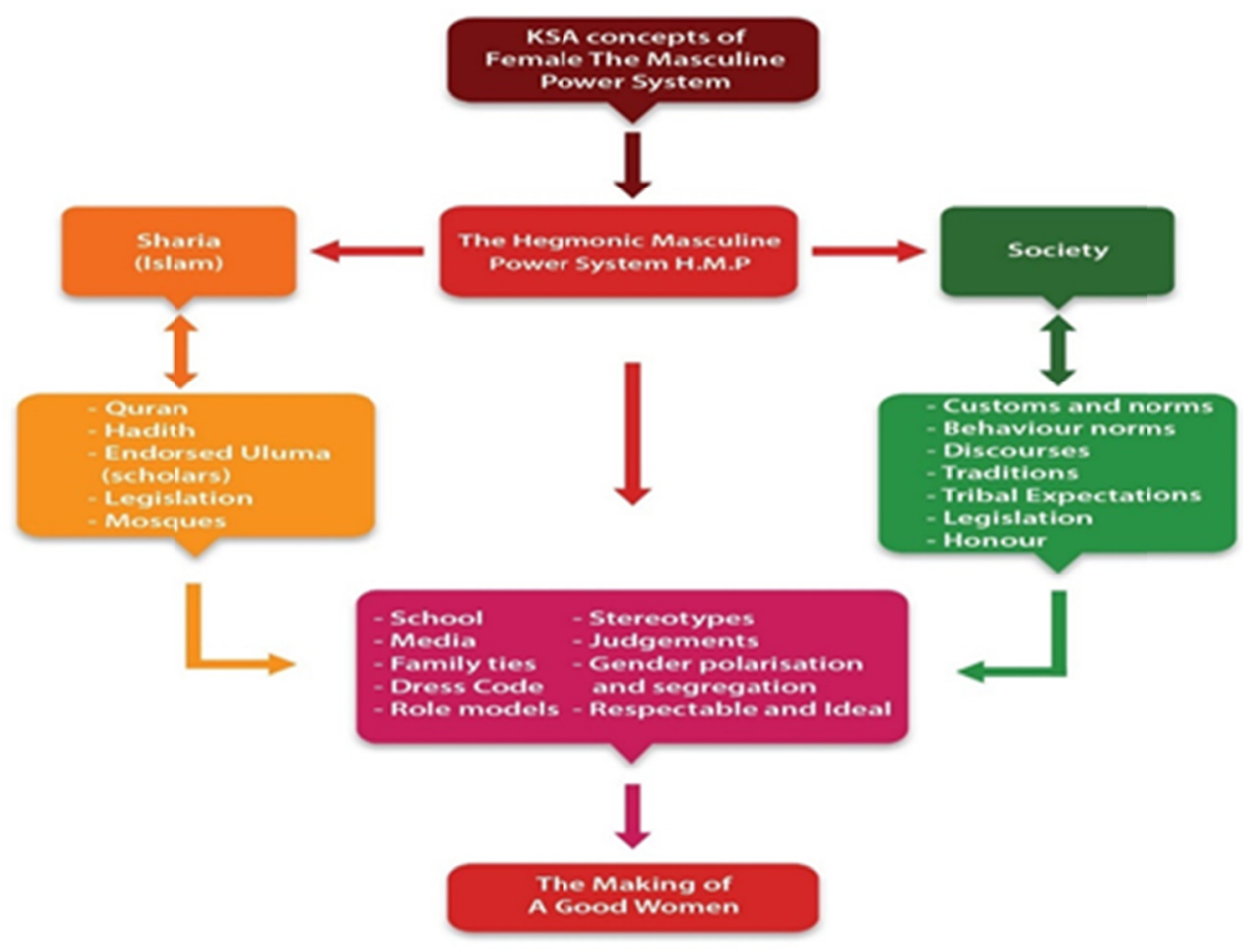

Figure 2. The making of a 'good woman'

Source: Al Zahrani, 2016.

\section{1 'Two Worlds' Model}

To consider the influences on girls at the pre-school stage of life in KSA, our vision must extend to the identity and role they may yet fulfil in the future 'the making of a good woman'. The pictorial diagram above demonstrates that these young girls are living within quite complex social paradoxes, where they are learning to balance and negotiate contradictions to become acceptable females in the KSA. On one hand they are expected 'in the private domain' to be feminine in the extreme, in appearance, dress and behaviour. However, in public, femininity must be covered and is bounded through shame and fear. (Z.SH) stated, '... young girls shouldn't walk in the street and also the streets are dangerous'. In another example of controlling the appearance of girls (GH.H) stated, 'If she is going to play football, they are going to shave her hair'. By contrast, another child implied that she would comply but then, '... after that she can play and do whatever and nobody will know about her' (A.M). This is similar to Goffman's (1967) front stage/back stage metaphor-where the dominants and subordinates are privy to a public transcript and hidden transcript, which subordinates are free to disregard in the private domain as long as they show public etiquette and deference in the public domain. The research found that young girls in the KSA can negotiate these variant social norms in their social and cultural framework. As they move or 'shift' between one environment and another (i.e., public and domestic), they adapt their external behaviour and appearance according to cultural expectation. Based on this, I propose what I call the 'Two Worlds Model': 


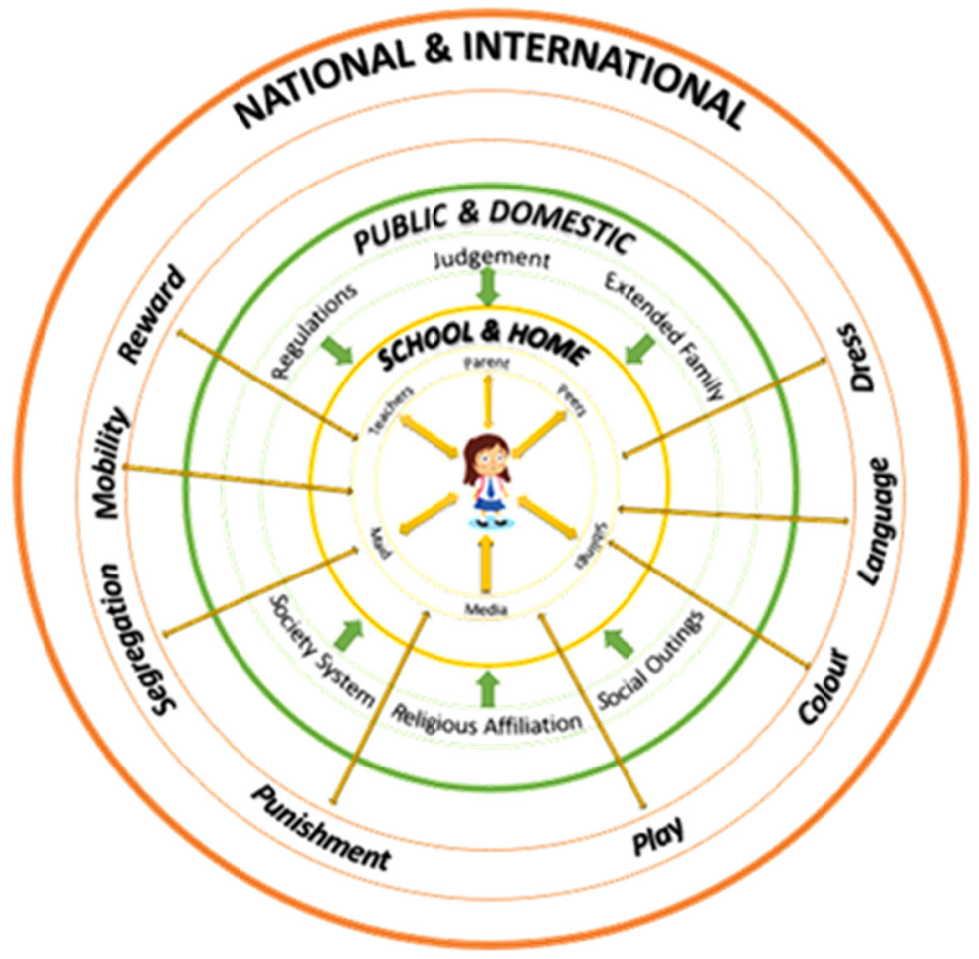

Figure 3. The arenas through which young girls are shifting

Source: Al Zahrani, 2017.

My model was greatly influenced by Bronfenbrenner's (1979) theory of ecological systems, in which he considers the external factors in the human development of a child. He states that a child: 'becomes capable not only of participating actively in that environment but also of modifying and adding to its existing structure and content' (Bronfenbrenner, 1979, p. 47). Young girls adapt their traits, behaviour and appearance according to the expectations of their mandated environments (e.g., parents, teachers, extended family). The influence of the mandated environment on a child can lead to different perceptions of skillfulness and strength. In the private domain a female can be viewed as strong. For instance, (S.M) stated: 'Mummies can cook, read and work at the same time'. This is supported by Bronfenbrenner, who elaborates how a child can be influenced by her mother, who becomes skillful at raising her child while also engaging in more than one 'essential activity' (Bronfenbrenner, 1979, p. 48). This is consistent with Martin and Ruble's (2004) postulation that children are 'gender detectives', actively seeking gender information to categorise gender identity and role. Moreover, in the KSA, the gender roles and identity differ from the public to the private domain, as each environment has alternative expectations of females, leading them to change their external manifestations of 'behaviour and appearance' accordingly.

There are six distinct environments a young female may encounter in the KSA: school, home, public, domestic, national and international. In each of these, the young female is expected to negotiate a multitude of factors and influences that are part of the societal framework. In this research, it was clear that the school and home environments reciprocally reinforce the gender segregation positioning with which a young girl must comply in order to be a heteronymic child who both accepts, and functions within, the 'two world model'.

At pre-school, a young girl studies the same topics as a young boy. However, many researchers have highlighted that, even universally, many educational establishments and teachers assign different roles and expectations according to gender (Chapman, 2016). In this study, one girl (S.M) stated that teachers have specific expectations about how the girls should behave in the school environment: 'the teachers in our school wanted us to maintain cleanliness'. This influence on young female roles leads girls to modify their play, dress, and activities according to what is regarded as a norm in their specific school community to gain reward and acceptance. In the home environment, a girl's femininity is maintained or 'protected' by many factors. One is fear: 'Her Mum will kill her with the knife if she ever goes out with the bike in the street' (R.A) and 'she will hit her'. Many of the children were familiar with stereotypical images and activities associated with her gender. (SH.A) stated: 'My Mum is always cleaning, and those pictures [of men doing domestic duties] I see only on T.V.' 
This highlights how girls, even at a young age, can distinguish differences associated with female role expectations at home, nationally or internationally. Moreover, young females are aware that, even in the public environment, different expectations apply to them or to other females; for instance (SH.A) stated: 'Because she [Mum] is in the mall, she finished her work and went straight to the mall with her driver', showing she is aware of her society's regulations. Once a young girl leaves her home and even her public environment, she encounters different models. In this case, the young girl should be able to construct subjective characters in a fluid manner, 'produce, challenge, reproduce then transform' her actions in various settings (Barrett, 1980, p. 97). A young girl depicted within the two worlds theory would 'shift', which Simpson (1997) explains as adaptation within each arena; this is similar to Kohlberg's theory (1984), where he states that cognitive ability and content for a child are constructed and shift as they grow. This study suggests that, as the young girl develops, she will acquire experience in more domains, and in each of these environments she will have to insert herself into the discourses she believes in and values, with reference to gender and identity.

\subsection{Girls Successfully Navigate Two Worlds to Maintain Female Gender Identity}

Young girls in the KSA exist in two juxtaposed worlds: the 'feminine' world, in which feminine attributes are accentuated, expected and recompensed and the 'un-feminine' wider world, in which these same attributes are hidden and restrained. The data revealed that the young subjects of this study, girls aged four to six years, realised that gender was situationally varied and were already able to navigate with skill between these worlds, using complex syntheses to switch between them: 'Mum is driving [only] in the desert' (L.N). Presumably, this mother would not be seen by others and thus her mother's reputation as a 'good woman' would be maintained, showing that the preservation of her good reputation depends upon the society and not the act itself. Another child talked about enjoying 'playing football', but realised she had to stop when her 'father saw her playing' (M.N), illustrating that gender role and identity is situational, depending upon who is watching. Children develop the knowledge and skills necessary to live and thrive in any given society (Weible \& Dromsky, 2002). In post-structuralist theory, children position themselves within discourses of masculinity and femininity; as children, perhaps these arenas are more accessible (Davies, 1989). The results suggest that this may be the case. This extract shows how a child uses her moral reasoning about social gender expectations to navigate her role and identity: 'she will say that she is going to wash the dishes and then after that she can play and do whatever and nobody will know about her' (A.M). The young girls were keenly aware that, in their society, gender accessibility, gender mobility and gender participation are restricted: for example, that females should not enter the public domain alone or drive or ride a bicycle in public. However, they also knew that the situation can change, that in some instances this rule should be applied and in others it could be more lenient in application - a female can ride a bicycle but not outside her own garden (correlating with the previous comment that gender behaviour is situationally varied).

Hermans (2001, p. 325) refers to the 'matrix of internal and external positions', for females in the KSA: these positions are twofold in each of the two domains: the inner female world and the external female world; internal female public positioning and that expected for external female public identity. The findings revealed that the female children understood these gender positions of appropriate dress. One of the books used as a prompt depicted a female dressed in traditionally masculine attire. The children unequivocally rejected this representation, exclaiming that a female should wear only pinks and purples, that their clothes should be fluffy and that females should wear high heels. This could be regarded as typical feminine attire. Notably, though, they did not say she had to be covered with a ' $h i j a b$ ' or 'nikab', which are the standard adult female attire in the KSA. However, the children also knew that females should be covered when in the public domain. This demonstrates that the children thought of dressing for two environments: one where they could be feminine and would in fact be judged (a form of punishment) - 'people will laugh!' (L.K) — if they were not; and another, where femininity should be hidden. In their role-play, some children dressed themselves in an 'abaya' and 'hijab'. There were different ideas or notions of acceptable activities, as a young girl said that she could have a bicycle but that 'it should be pink' (L.N). It is important to note that she said she had the right to a bike: it does appear, then, that perceptions are changing, albeit in a limited gender framework. The research highlighted that children at this stage actively define their gender discourses and many of the participant girls revealed typical feminine gender discourses, such as body movement, wearing feminine clothes and talking about beauty and fashion. This was similar to Blaise's (2005b) study in Australia, which demonstrated that pre-school children actively maintain and even regulate their societal gender norms in the classroom.

\section{Findings from the Research}

In the KSA, societal expectations for gender roles and gender identity, in respect of females, are not prescribed in adulthood: the blue print and foundations for such are drafted and constructed in early childhood. The 
patriarchail society of the KSA, where males largely dictate what females can do (Doumato, 2010), has decreed cultural and social norms that make 'a good woman'; by extension, they also have felt the need to construct firstly 'a good girl' and many notions of what constitutes such are derived from discourses propogated by the same. However, it is Saudi society, as a whole, that first shapes the child's world in the vision of the woman that she may become; after this, they then narrow her existence to the point of childhood. This runs alongside the 'blueprint' that charts her development towards the identity and role that her culture and her society expects and in fact needs her to embody, so ensuring that she is recognised as 'a good woman'.

The research confirmed three important theoretical and practical positions regarding young girls in the KSA:

1) Females have to live, function in, and dress for two different worlds - a social paradox which they must navigate successfully in order to sustain an acceptable female identity in these two worlds. There exists one world in which she must be very feminine in both behaviour and dress; where she will be judged by other females and males (who are privy to her private world) according to prescribed criteria on what constitutes 'a good woman' - a female by virtue of feminine appearance. In the other world, however, this same femininity has to be denied, with female characteristics and features hidden, and activities and mobility restricted by gender. In the latter another set of criteria exists, applied by patriarchal dominance, where the whole society will judge if she is a 'a good woman' - an accepted female through feminine constraints. In this world she is judged to be a 'good woman' by the amount of restraints she imposes on her femininity through her outward appearance and manner with others, particularly males who are not regarded as one of her 'mahram' - (male guardians).

2) Traditionally Saudi Arabia has been made up of many tribes, in what might be called pastoral societies. The tribal/pastoral traditions, beliefs and ideologies relating to the purity and chastity of the female have fed into the development of the sense that the female body does not belong totally to that female - it is the property of her husband and male guardians where the maintenance of her female chastity and moral ideology supercedes everything and anyone.

3) Finally, as young girls grow up, and in order to have moral citizenship, a shift is seen from female gender autonomy to heteronomy, decreed by the authority which creates her identity through rules and discourses; her society. Females must negotiate their existence within the hegemonic masculine powers which propagate and promulgate the ideals and traditions within these moral discourses to construct a female that they believe will determine what makes a good woman.

\section{Conclusion}

The children were very clear in what was relevant to them as a female within the context of their day in pre-school. These young girls were aware of gender roles and identity within the context of their home and the roles that females adopt in maturity, and it was noted that, although other female gender identities were experienced, such as in story books, on television, or in discussions using prompt cards, the children were absolute and final about their notions of female gender identity and role according to their perspective.

In order for the individual to adapt to the social world and develop her moral heteronomy, then both the inherent nature and the reality of the world need to be taken into consideration, together with deliberation upon the most powerful influential environmental forces (Bronfenbrenner, 1979). The KSA has strong, fixed ideals of what role and identity each gender should have, and this reverberates from each of the layers of influence that constitute and construct a person's life. Ultimately, we are only a composite of the discourses to which we are privy to and unless we ostracise ourselves from society and any outside influences, these discourses are continuous and changing.

The logic and wisdom of Islam and the rights it gives to women to be respected and protected within a society that is pious, good and beneficial for both genders who reside within it. Many of us are comforted by discourses on the wisdom of Islam - after all, the basis of many cultural practices in KSA — which reinforce our love of our culture and my religion. These discourses highlight the positive aspects of cultural practices, and in reading them bring an understanding and conviction to accept the notion of 'social order' within the KSA, as well as its dual purpose in protecting females and in the preservation of purity and piety. If we look at another example of a society in a different country, would we find that females there are also constructed by their society's compliance towards hegemonic masculine powers that construct an appropriate female that suits the needs of that society? This attitude might or might not be a suitable construction for the needs of the KSA society. People need to fit into their own society, their own values and their own constructs of what they see as right or wrong. Each one may be right and each one may be wrong; it is all dependent on a person's subjectivity and positioning and these are developed through discourses, imitation and ideologies. This research helped foster a realization of some of the contradictions that exist within the KSA culture and the society's attitude towards men and women. 
However, KSA females are proud to be a woman, and many are proud to be a Muslim woman. By the same token, they are proud to be a Saudi Muslim woman. The KSA has made lots of changes to better the situation of females and its SaudiVision (2030) has plans and policies to develop the situation to be more amenable for female independence. However, it is sufficient to say that the most influential means of change will evolve through education and choice.

\section{References}

Al-ghamdi, H. A., \& Abdul-aljawad, N. M. (2010). The development of the educational system in the Kingdom of Saudi Arabia (3rd ed.). Riyadh: Al-Rushd Press.

Alzahrani, M. (2015). Nahila and the bike. Oxford Brookes University. Oxford.

Barone, T. (2001). Touching eternity: The enduring outcomes of teaching. New York: Teachers College Press.

Barrett, M. (1980). Women's Oppression Today: Problems in Marxist Feminist Analysis (4th ed.). London: Verso.

Bové, P. (1990). Discourse. In F. Lentricchia \& T. McLaughlin (Eds.), Critical terms for literary study (pp. 50-65). Chicago, Ill.: University of Chicago Press.

Bronfenbrenner, U. (1962). The Role of Age, Sex, Class and Culture in Studies of Moral Development. Religious Education, 57(S4), 3-17. https://doi.org/10.1080/003440862057S402

Bronfenbrenner, U. (1979). The Ecology of Human Development. Experiments by Nature and Design. Cambridge, Mass.: Harvard University Press.

Bronfenbrenner, U. (1986). Ecology of the Family as a Context for Human Development: Research Perspectives. Developmental Psychology, 22(6), 723-742. https://doi.org/10.1037/0012-1649.22.6.723

Chapman, R. (2016). A case study of gendered play in preschools: how early childhood educators' perceptions of gender influence children's play. Early Child Development and Care, 186(8), 1271-1284. https://doi.org/10.1080/03004430.2015.1089435

Christou, A. (2006). Narratives of Place, Culture and Identity: Second-Generation Greek-Americans Return 'Home'. Amsterdam: Amsterdam University Press. https://doi.org/10.5117/9789053568781

Clough, P. (2002). Narratives and Fictions in Educational Research. Buckingham: Open University Press.

Davies, B. (1989). Frogs and Snails and Feminist Tales: Preschool Children and Gender. Sydney: Allen and Unwin.

Davies, B., Dormer, S., Gannon, S., Laws, C., Rocco, S., Taguchi, H. L., \& McCann, H. (2001). Becoming schoolgirls: the ambivalent project of subjectification. Gender and Education, 13(2), 167-182. https://doi.org/10.1080/09540250124848

Doumato, E. A. (2010). Saudi Arabia. In S. Kelly \& J. Breslin (Eds.), Women's Rights in the Middle East and North Africa: Progress amid Resistance (pp. 425-458). New York, N.Y.: Rowman and Littlefield Publishers.

Duveen, G. (1993). The Development of Social Representations of Gender. Papers on Social Representations, 2(3), 1-77.

Duveen, G., \& Lloyd, B. (1990). Social representations and the development of knowledge. Cambridge: Cambridge University Press. https://doi.org/10.1017/CBO9780511659874

Estola, E., \& Elbaz-Luwisch, F. (2000). Teaching bodies at work. Journal of Curriculum Studies, 35(6), 697-719. https://doi.org/10.1080/0022027032000129523

Fisher, W. (1984). Narration as a human communication paradigm: The case of public moral argument. Communication Monographs, 51(1), 1-122. https://doi.org/10.1080/03637758409390180

Gilborn, D., \& Mirza, H. S. (2000). Educational inequality-mapping race, class and gender: A synthesis of research evidence. London: Office for Standards in Education. https://doi.org/10.1177/136548020100400215

Göckeritz, S., Schmidt, M. F. H., \& Tomasello, M. (2014). Young children's creation and transmission of social norms. Cognitive Development, 30, 81-95. https://doi.org/10.1016/j.cogdev.2014.01.003

Kohlberg, L. (1966). A cognitive-development analysis of children's sex role concepts and attitudes. In E. Maccoby (Ed.), The development of sex differences (pp. 82-172). Stanford, California: Stanford University 
Press.

Kohlberg, L. (1984). The Psychology of Moral Development: The Nature and Validity of Moral Stages (Essays on Moral Development, Vol. 2). London: Harper and Row.

Kostiner, J. (1990). Transforming Dualities: Tribe and State Formation in Saudi Arabia. In P. S. Khoury \& J. Kostiner (Eds.), Tribes and State Formation: In the Middle East (pp. 226-251). Los Angeles, California: University of California Press.

Maccoby, E. E. (1998). The Two Sexes: Growing Up Apart, Coming Together. Cambridge, Mass.: Harvard University Press.

Maccoby, E. E. (2002). Gender and group process: A developmental perspective. Current Directions in Psychological Science, 11(2), 54-58. https://doi.org/10.1111/1467-8721.00167

MacIntyre, A. (1985). After Virtue: A Study in Moral Theory (2nd ed.). London: Duckworth.

Paechter, C. (2006). Reconceptualizing the gendered body: Learning and constructing masculinities and femininities in school. Gender and Education, 18(2), 121-135. https://doi.org/10.1080/09540250500380489

Piaget, J. (1932). The Moral Judgment of the Child. New York: Free Press.

Rajab, A., \& Wright, N. (2018a). Government constructions of the pedagogical relationship between teachers and children in Saudi preschool education: Issues of adoption or adaptation. Pedogogy, Culture and Society, 26(4), 547-560. https://doi.org/10.1080/14681366.2018.1427140

Rajab, A., \& Wright, N. (2018b). The idea of autonomy and its interplay with culture in child-centered education: Evidence from practitioners in preschools in Saudi Arabia. Early Years, 40(2), 174-187. https://doi.org/10.1080/09575146.2018.1434134

Rogoff, B. (2003). The culture nature of human development. Oxford: Oxford University Press.

Royal Embassy of Saudi Arabia, Washington, D.C. (2015). Retrieved October 22, 2015, from https://www.saudiembassy.net/education

SaudiVision. (2030). Retrieved from https://vision2030.gov.sa/en/search/node/education

Sedgwick, R. (2001). Education in Saudi Arabia. World Education News + Reviews, 1 November. Retrieved October 19, 2015, from https://wenr.wes.org/2001/11/wenr-nov-dec-2001-education-in-saudi-arabia

Simpson, A. (1997). It's a game: The construction of gendered subjectivity. In R. Wodak (Ed.), Gender and Discourse (V31, 3-4, pp. 197-224). London: Sage. https://doi.org/10.4135/9781446250204.n9

Smith, A. B. (2004). How do infants and toddlers learn the rules? Family discipline and young children. International Journal of Early Childhood, 36(2), 27-41. https://doi.org/10.1007/BF03168198

UNDP. (2003). Saudi Arabia: Women in public life. In United Nations Development Programme. Program on Governance in the Arab Region. Retrieved May 25, 2017, from $\mathrm{http} / /$ hdr.undp.org/en/content/saudi-arabia-human-development-report-2003

UNICEF (2013). Education: Adult literacy rate-Percentage (Saudi Arabia). Retrieved May 25, 2016, from https://data.unicef.org/topic/education/literacy/

Vygotsky, L. S. (1978). Mind in Society: The Development of Higher Psychological Process. Cambridge, Mass.: Harvard University Press.

Vygotsky L. S. (1987). 'Thinking and speech', Notes to the Russian Edition. In R. W. Rieber \& A. S. Carton (Eds.), The collected work of L.S. Vygyotsky (Vol. 1: Problems of general psychology, pp. 375-384). New York, N.Y.: Plenum Press.

Walkerdine, V. (1997). Daddy's Girl: Young Girls and Popular Culture. Cambridge, Mass.: Harvard University Press.

Weible, T. D., \& Dromsky, A. J. (2002). Early Childhood Social Studies. In O. N. Saracho \& B. Spodek (Eds.), Contemporary Perspectives on Early Childhood Curriculum (pp. 155-170). Greenwich, Conn.: Information Age Publishing. 


\section{Copyrights}

Copyright for this article is retained by the author, with first publication rights granted to the journal.

This is an open-access article distributed under the terms and conditions of the Creative Commons Attribution license (http://creativecommons.org/licenses/by/4.0/). 